\title{
An evaluation of the status of five threatened plant species in the Pyrenees
}

\author{
María B. García ${ }^{\mathrm{a}, *}$, David Guzmán ${ }^{\mathrm{b}}$, Daniel Goñi ${ }^{\mathrm{c}}$ \\ ${ }^{a}$ Estación Biológica de Doñana (CSIC), Avda. María Luisa s/n, Pabellón del Perú, 41013 Sevilla, Spain \\ ${ }^{\mathrm{b}}$ Instituto Pirenaico de Ecología (CSIC), Apdo. 64, 22700 Jaca, Spain \\ ${ }^{\mathrm{c}}$ LARRE S.C., Monasterio de Iguácel, 11, 3 B, 22700 Jaca, Spain
}

Received 7 March 2000; received in revised form 9 January 2001; accepted 15 May 2001

\begin{abstract}
In this paper we assess the conservation status of five of the most threatened species in the Pyrenean range (listed in the European Habitats Directive), and present updates of their distribution, reliable censuses to estimate population sizes, population growth rate, population structure, longevity, reproductive success and frequency of herbivory. Recent surveys and careful censuses revealed that the four taxa exclusively restricted to rocky habitats (Borderea chouardii, Androsace pyrenaica, Petrocoptis pseudoviscosa, Petrocoptis montsicciana) have more populations and/or individuals than previously thought. The remaining species, an orchid $(C y p r i-$ pedium calceolus), showed an important decline in population number. So while the rupicolous taxa might be considered naturally rare, the orchid is becoming rare. We failed to find evidence of current poor performance within populations, as recruitment was detected, population growth rate was quite stable in recent years, fruit and seed set was apparently adequate, and herbivory and predation were absent or very low. Additionally, most of the species show a long life span, which might buffer them against demographic and environmental stochasticity in absence of human disturbance. (C) 2001 Elsevier Science Ltd. All rights reserved.
\end{abstract}

Keywords: Threatened plants; Area distribution; Population size; Population growth rate; Life span

\section{Introduction}

Lists of threatened plant species are frequently based on previously generated lists of endemic or rare plants, together with notable cases of species that are declining due to harvesting or habitat destruction. The underlying assumption of greater vulnerability and risk of extinction of these taxa is based on a greater influence of genetic factors (i.e. resulting from inbreeding depression and genetic drift) as well as environmental and demographic stochasticity (Shaffer, 1981; Menges, 1992) for species with reduced population sizes or limited distributions. It is, however, much more difficult to quantify to what extent a species is "threatened" under natural conditions or particular scenarios, in the formal sense that it faces a risk of extinction in the immediate, near, or medium-term future (IUCN, 1994). This is the

* Corresponding author. Tel.: +34-954-232-340; fax: +34-954621-125.

E-mail address: garciam@cica.es (M.B. García). difference between a theoretical versus empirical approach. Thus, lists of threatened taxa usually contain many species with reduced or highly scattered distribution, due to mixed historical or current, real or uncertain causes, and whose limited distribution might have unknown consequences.

The publication of the "Habitats Directive" (Anon., 1992) by the European Union, which identified species and habitats worth preserving, revealed that $40 \%$ of the EU priority species are within Spain (Morillo and Gómez-Campo, 2000). This stresses the need for national and regional governments to develop strategies to manage such singular biodiversity. In particular, the Spanish Regional Government of Aragón recently published a list containing more than 100 threatened species (Anon., 1995b), and the first official "recovery plan" for a plant species (Anon., 1995a; see also Bañares, 1994). Population viability analyses were not available for any of them, and the demographic and biological information was limited for most at the time of being listed. Thirteen were included in Appendix II of the "Habitats 
Directive", and funding was provided by the European Union to develop a LIFE project in order to improve their conservation situation. Five out of those 13 species occur in the Pyrenean range, all except one growing on very specific habitats and mostly inaccessible places.

In this paper we describe the approach undertaken to assess the real vulnerability of these species. Following Schemske et al. (1994), we have not addressed the traditional question of "why these species are so rare?" Rather, we were interested in questions of dynamics, such as: "is there any evidence that these species are declining or are currently not performing well?" We were also concerned with finding life-history traits that enhance or buffer population size fluctuations.

We have based our study in three general premises. First, our overall knowledge of plant species distribution is usually both biased and limited. For example, we know much better the distribution of lowland than alpine species. Therefore, although we can get an idea about their rarity from their frequency in herbaria, we cannot draw conclusions about their real distribution or dynamics unless we make repeated efforts to find them over time throughout their potential habitat. Second, some species are intrinsically rare due to a variety of factors (Stebbins, 1980; Kruckeberg and Rabinowitz, 1985), while other species are becoming rare because of direct or indirect human disturbance. So, the direction and rate of demographic change might be as important as population size or distribution in evaluating the risk of extinction. Finally, while the concept that a species is threatened implies at least a minimum degree of rarity, it cannot be assumed that all species with narrow distributions are threatened, as not all of them share the same degree of vulnerability. Thus, we need a better understanding of the demography of a species before declaring its viability, and better knowledge on its biology in order to predict its vulnerability and "response capacity" in the face of natural stochasticity or potential future disturbances.

With this in mind, in this paper we will delimit the "conservation problem" for each target species by using an increasing intensity approach (Menges and Gordon, 1996). Through field surveys and monitoring, our goal was to improve our understanding of their distribution, demography and some biological factors directly involved in their persistence. This information will help to classify each species according to the criteria of World Conservation Union Red List (IUCN, 1994) and the modifications recently proposed by Keith (1998).

We specifically wished: (1) to determine species distributions by examining known, historical and potentially suitable areas, confirming current populations, finding new ones, or documenting local extinctions; (2) to quantify population sizes through careful censuses and calculate population trends from monitoring in permanent plots; (3) to describe population structures, in order to detect possible unbalanced life stage distributions that could point out possible performance problems; and (4) to examine reproduction and herbivory as indicators of population performance. Our efforts toward achieving these objectives made it clear that the five species differed in the amount of attention they warranted. Accordingly, a detailed demographic study was focused on the three species with the highest priorities. Matrix population models were developed incorporating stochasticity in order to project population dynamics and long-term viability. Detailed results of these will be the subject of following papers.

\section{Methods}

\subsection{General information on the species investigated}

The five species studied were those included in the Habitats Directive (Anon., 1992) that occur within the limits of the Aragonese Pyrenees.

Borderea chouardii (Gaussen) Heslot was discovered and named in the 1950s (Gaussen, 1952). This is a paleoendemic species belonging to a mainly tropical family (Dioscoreaceae). It is known to occur exclusively in an area of less than 1 square kilometre of rugged mountains in the Spanish Pyrenees on northwardsfacing limestone cliffs. The total population has been estimated at no more than 500 individuals (GomezCampo and Malato-Beliz, 1985; Sainz Ollero et al., 1996), most of them growing on inaccessible shaded crevices of limestone walls and overhangs. Its precarious demographic situation, together with the fact that it seems to have been affected by public works (a dam and a road), result in this plant being considered as one of the most endangered organisms according to the regional, national, and European lists. An official recovery plan has recently been implemented (Anon., 1995a).

Androsace pyrenaica Lam. (Primulaceae) is an endemic plant of the central Pyrenees considered at risk of extinction in both the national and regional listing. It grows in rocky crevices, on granite, schist, sandstone or quartzite, between 1500 and $3000 \mathrm{~m}$ a.s.l., with variable, but often southerly, exposures. At the time of promulgation of the Habitats Directive (1992), it was known to occur in 17 locations on the French side of the mountains, and only two on the Spanish side. Knowledge of its distribution has increased considerably in the last few years, as 20 new localities have been added to the Spanish distribution (Ferrández et al., 1993). Sainz Ollero et al. (1996) estimated the total population size to be no less than 10,000 individuals.

Petrocoptis pseudoviscosa Fernández Casas (Caryophyllaceae) is a relatively recently described taxon (Fernández Casas, 1973), endemic to just one valley in the Pyrenees according to Montserrat and Fernández 
Casas (1990). This complicated genus, endemic to the Iberian Peninsula, is closely related to Silene and has been restructured several times (Mayol and Roselló, 1999). The two main taxonomic floras used in Spain (Montserrat and Fernández Casas, 1990; Walters 1993) do not agree on the number of species belonging to this genus nor the taxonomic validity of this species in particular. This is also a rupicolous taxon occurring mostly on limestone cliffs and overhangs in deep gorges. Prior to this study, there were five known populations comprised of approximately 10,000 individuals (Sainz Ollero et al., 1996).

Petrocoptis montsicciana O. de Bolòs \& Rivas Martínez (Caryophyllaceae) was also described relatively recently (Bolos and Rivas-Martínez, 1968). It is endemic to the Spanish Pyrenees, but is found in two regions: Catalunya and Aragón. Before this study, 15 localities $(1 \times 1 \mathrm{~km}$ squares $)$ in Catalunya and six in Aragon were known (Sainz Ollero et al., 1996). Like the former species, this is a rupicolous taxon, limited to limestone cliffs in warmer areas. Though there was no previous estimate of the total number of individuals in Catalunya, the estimated population in Aragón was somewhat more than 400 individuals (Sainz Ollero et al., 1996).

Cypripedium calceolus L. (Orchidaceae) is not endemic to the region, but is a holartic species whose Pyrenean populations constitute its south western limit in Europe (Hulten and Fries, 1986). The number of populations seems to have decreased considerably in recent years and it is now considered either extinct or extremely rare in several European countries (Stewart, 1992; Kull, 1999). Populations in the Pyrenees occur on both sides of the mountain range. On the French side, it has been described at four locations (Juanchich et al., 1991; Lazare and Royaud, 1994). In Spain, three new populations have been recently discovered in Catalunya (Aymerich, 1999); one population was known in Aragón prior to the present project (Lazare et al., 1987; Sainz Ollero et al., 1996). There were, however, reports, not formally documented, of another eight locations, most of which were supported by photographs of flowering individuals. The estimated overall number of individuals varied substantially depending on the author of the estimates, from a total of several hundred (Sainz Ollero et al., 1996) to more than one thousand flowering individuals (Lazare et al., 1987). The well known population in the Spanish Pyrenees occurs near the French border between a beech forest and a meadow.

\subsection{Study carry out}

We surveyed intensely mainly during 1997 . Monitoring of population sizes and reproductive parameters were carried out from 1994 to 2000, depending on species, and in these cases the range and/or average \pm standard deviation is given. The study was limited to populations within Aragón.

\subsubsection{Distribution}

For each species, we constructed a detailed map on a $1 \times 1 \mathrm{~km}$ UTM grid, indicating its potential habitat (on the basis of previous information of its distribution), and populations known from publications, herbaria, and personal communications by naturalists, photographers, and nature guides.

The rupiculous habitat of the species and inaccessibility of the potential and known populations necessitated that we plan survey routes carefully. All known or "suspected" populations were visited except a few small ones that had been reached by colleagues about 5 years ago. The most important potential habitats were also visited in order to look for new populations. Telescopes and binoculars were used to inspect sites which could not be reached on foot. Habitat availability and species occurrence were recorded on 1:50000 maps. Because individual populations were also sometimes patchy, nuclei (defined as groups of plants separated from others within a population) were delimited on 1:5000 maps.

Following the surveys, the "extent of occurrence" (the area contained within the shortest continuous imaginary boundary which encompasses all the known sites of present occurrence), and the "area of occupancy" (the occupied area within the extent of occurrence, excluding cases of vagrancy) were calculated for each taxon using the $1 \times 1 \mathrm{~km}$ UTM grid as unity, following the IUCN proposal (1994).

\subsubsection{Censuses}

For the orchid, the only species growing on soil, the census was relatively simple. The whole area was inspected in June (after emergence of seedlings and vegetative shoots), by three people who counted all individuals.

The other four species grow on generally inaccessible rocky cliffs at medium to high elevations (800-2700 m.a.s.1.), thus precluding the detailed observations possible with the orchid. Therefore, we used a different censusing method. Once a potential population or nucleus was located on a cliff, we counted the number of units that could be distinguished by then naked eye, with binoculars (magnification $\times 8$ ) or with a telescope (magnification $\times 20-60$ ). Such units were named "visual units". This method did not allow us to distinguish either small plants (e.g. seedlings) or individual plants growing in clumps, and therefore understimates population size. To adjust for this bias we calculated a correction factor in the following way: in one or more accessible areas we first counted "visual units" from a distance, and then recounted all the plants "close-up." The ratio between both measurements (real number of individuals/number of visual units) was used to estimate the total number of individulas from the number of visual units recorded in inaccessible areas or populations. 
As the distance to the plants varied considerably, two correction factors were calculated depending on the optics involved in the census. Factor F1 was used when plants were either closer than $10 \mathrm{~m}$ and counted without optical aids, or between 10-40 m and observed through binoculars. Factor F2 was used when plants were between 40-200 $\mathrm{m}$ and observed with binoculars, or further than $200 \mathrm{~m}$ and viewed with the telescope. This method was applied to as many areas as possible, but some were absolutely inaccessible (which happened occasionally in the case of $A$. pyrenaica and P. montsicciana), and therefore neither F1 nor F2 could be properly calculated. In those cases, for each species we calculated the corresponding weighted average correction factor from different areas or populations.

\subsubsection{Monitoring}

For the two species with the narrowest distribution and for the suspected declining orchid, permanent plots were monitored for 4-6 years. It was necessary to set two scaffolds to get to individuals of $B$. chouardii. The area used for $P$. pseudoviscosa was almost completely accessible. Fourteen $1-\mathrm{m}^{2}$ plots were placed at random throughout the largest population of $C$. calceolus. At the end of the reproductive period every year, the number of plants alive, new recruits and deaths were recorded. The finite growth rate was calculated as the ratio between the number of individuals recorded in one year and the year before. From 100 to more than 500 plants were monitored in each population.

\subsubsection{Population structure}

In accessible areas of rupicolous species all individuals were checked and classified into three categories: seedlings (younger than 1 year, recognized if cotyledons were still present in some species, or recorded as new recruited plants in other species because all individuals were mapped in the previous census), non-reproductive plants (juveniles + non-flowering plants the year of study), and flowering (reproductive) plants. This latter category might underestimate the "mature individuals" category used by the IUCN, because not all of them will reproduce each year. Males and females were counted separately in B. chouardii. In the orchid, seedlings are not possible to distinguish from new clonal shoots. To circumvent this problem and estimate frequency of recruitment, censuses were carried out at the beginning and at end of the season (June and September) in permanent plots. We assumed all shoots detected in the second census were new (actually they all were quite small). This method underestimates recruitment because it discounts those new shoots already present in the first census, but allows estimation of their minimum percentage. Surveys were carried out at the end of the reproductive season for all species except $A$. pyrenaica and $P$. montsicciana, whose examination took place during flowering to better distinguish flowering individuals from far away. We do not know to what extent the frequency of seedlings might be influenced by the sampling date for these species, but seedling mortality has been lower than $10 \%$ between flowering and the end of reproductive season in the remaining species (unpublished data).

To obtain size distributions of individuals, the diameter of Androsace cushions, the number of $P$. pseudoviscosa rosettes, and Borderea and Cypripedium leaves, were counted in all accessible areas or monitoring plots.

\subsubsection{Life span}

Longevity of individuals was investigated when possible. The method described for B. pyrenaica (García and Antor, 1995) was applied to dead tubers of its congener B. chouardii $(\mathrm{n}=15$ still intact dead tubers after being taken out from crevices). This genus has the unusual feature that the annual aerial stem leaves a scar on the tuber surface, allowing for the estimation of minimum age. Several herbarium specimens of $A$. pyrenaica $(n=10)$ and fresh rhizomes of $C$. calceolus from a transplanting experiment $(n=30)$ were also examined. Spatial discontinuities in stem morphology, and nodes from which new leaves appeared were distinct enough for us to assume that they corresponded to seasonal growth, providing age of individuals with high certainty. No way of estimating the age in Petrocoptis was identified.

\subsubsection{Reproductive success}

The ratio of fruits to flowers (fruit set) at the end of the reproductive period was calculated for all species over 1-6 years. A fruit sample of each species was examined to assure that it contained developed seeds, and the ratio of seeds to ovules was calculated for some species and years.

\subsubsection{Herbivory and predation of reproductive parts}

When visiting populations, we estimated the proportion of herbivory (percent leaf area lost per plant, recorded at 10 intervals from $1-10 \%$ to $91-100 \%$ ) each checked individual had suffered, and counted the number of flowers or fruits preyed.

\section{Results}

\subsection{Distribution}

The overall distributions of the five species are shown in Fig. 1. Except for A. pyrenaica, each species occurred in very few populations (1-7), sometimes containing a number of nuclei close to each other. This withinpopulation fragmentation was partly imposed by the high habitat specificities of the species, which restrict them to very small and patchy areas. 
Table 1 shows the current number of populations, nuclei, and $1-\mathrm{km}^{2}$-UTM quadrats for each species. One new population of $A$. pyrenaica and three of $P$. montsicciana were found out. Newly added $1-\mathrm{km}^{2}$ quadrats ranged between 1 for $B$. chouardii and 8 for P. montsicciana. The distribution of the orchid, C. calceolus (the only species growing on soil instead of in crevices), showed a decline according to our information sources, as some of the nine previously known populations could not be relocated after repeated visits. Nevertheless, two more new nuclei were discovered near the largest known population, and one unpublished population (comprising four extensive nuclei for us, and corresponding to three populations according to our informant) was relocated.

\subsection{Population size}

Table 2 shows some demographic parameters of individual populations. After applying the correction factors

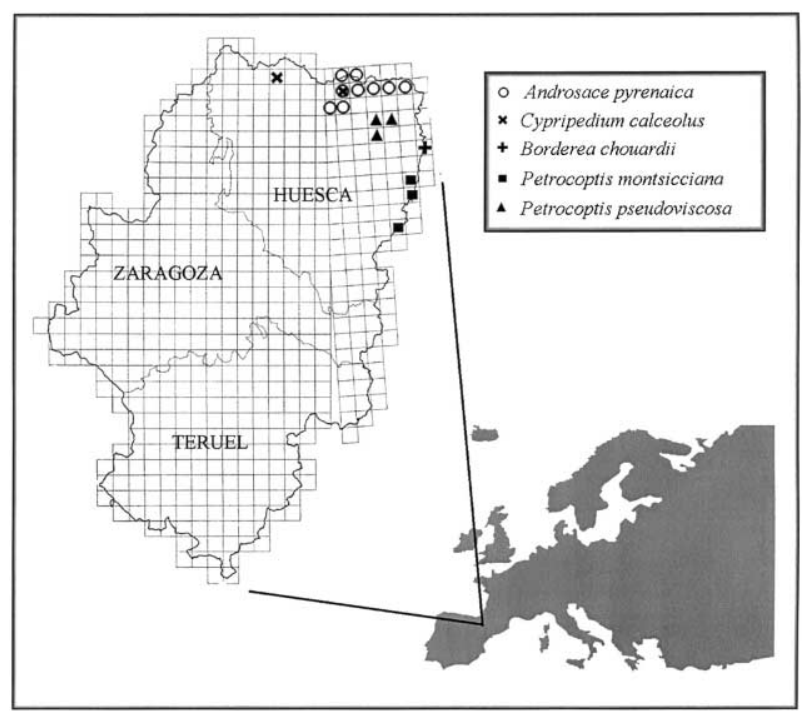

Fig. 1. Geographic distribution in the Aragón Pyrenees $(10 \times 10 \mathrm{~km}$ UTM squares) of the five plant species included in the study. for each species, (F1 and F2 depending on the distance to populations and the optical devices used, see methods), the estimates of population sizes increased by nearly two (F1) to eight (F2) times the number of "visual units" recorded by long-distance surveys. For $A$. pyrenaica, the species for which the most correction factors were obtained, the coefficients of variation for $\mathrm{F} 1$ and $\mathrm{F} 2$ were $19.6 \%$ and $26.7 \%$, respectively.

The total number of individuals per species ranged between more than 2,000 (1 population of $B$. chouardii) to almost 50,000 (P. pseudoviscosa, total of five populations), both species having their whole distribution area within the study region. Informants indicated that the few populations of $A$. pyrenaica not visited were all very small (less than 100-200 individuals after a rough corrected estimation), so that their contribution to the total size is low. It is important to keep in mind that our estimates of total population sizes are for populations within the regional limits of our study, but three of the five species (A. pyrenaica, P. montsicciana and C. calceolus) also occur outside the study area. Individual populations contained, on average, several hundred plants (Table 2), although very small populations (less than 10 plants) were also found.

\subsection{Population trends}

The finite rate of increase was near 1 for the rupicolous species (B. chouardii and P. pseudoviscosa), but varied more for the orchid population (Table 2). It can be concluded that population sizes have remainded considerably stable in the last 4-6 years for "inaccessible" plants.

\subsection{Population structure}

Fig. 2 shows the population structure for each species in terms of life stages. In most populations, a high proportion of the individuals were in the reproductive category. Flowering is the only means of reproduction for all species except the orchid, and this is the only

Table 1

The distribution of the species in Aragón ${ }^{\mathrm{a}}$

\begin{tabular}{|c|c|c|c|c|c|c|}
\hline Plant species & Country & $\begin{array}{l}\text { Populations } \\
\text { in Aragón }\end{array}$ & $\begin{array}{l}\text { Number } \\
\text { of nuclei }\end{array}$ & $\begin{array}{l}\text { UTM in } \\
\text { Aragón }\end{array}$ & $\begin{array}{l}\text { Total extent of } \\
\text { occurrence }\end{array}$ & $\begin{array}{l}\text { Current } \\
\text { overview }\end{array}$ \\
\hline Borderea chouardii & Spain (only in Aragón) & 1 & 3 & $2(2)$ & 1 & + \\
\hline Androsace pyrenaica & Spain (only in Aragón) + France & $26^{*}$ & $45^{*}$ & $35(?)$ & 2000 & + \\
\hline Petrocoptis pseudoviscosa & Spain (only in Aragón) & 5 & 60 & $11(11)$ & 22 & + \\
\hline Petrocoptis montsicciana & Spain (Aragón + Catalonia) & $7 *$ & $16^{*}$ & $12(25)$ & 200 & + \\
\hline Cypripedium calceolus & Northern hemisphere & $3 *$ & $7 *$ & $7(?)$ & Holarctic & - \\
\hline
\end{tabular}

a "Nuclei" means groups spatially well delimited within a population, due to the scattered distribution of the rocky habitat. An asterisk indicates that the species has additional populations outside the Aragón limits. The number in parentheses is the total range occupied by the species, measured as the total number of 1-km UTM grid squares. Occurrence is given in square $\mathrm{km}$. Current overview indicates whether our knowledge of the situation of the species has improved (+) or worsened (-) their situation after comparing previous and present information of distribution area (number of populations or nuclei). 
taxon that shows considerably more vegetative shoots. Twice as many males as females were found in $B$. chouardii. Relatively few seedlings were present in all populations of rupicolous species. Recruitment of $C$. calceolus, estimated from the difference in the number of shoots between the beginning and end of the season in 1997 , accounted for $16 \%$ of total plants. Plant size distributions were always skewed, with many more small than large individuals being present (Fig. 3).

\subsection{Life span}

Twelve out of the 15 tubers examined of $B$. chouardii were older than 100 years, and one was over 300 years old. Some reproductive individuals of the alpine cushion plant $A$. pyrenaica, as well as large rhizomes of the orchid, were estimated to be older than 30 years.

\subsection{Reproductive success}

Between nearly 1000 and 20,000 individuals were estimated to be sexually reproducing in every species (Table 2), and fruit set (fruits/flowers) was generally over $50 \%$ for all years and populations examined (Fig. 4). The highest value corresponded to the most threatened species, the dioecious $B$. chouardii (average of $84.3 \pm 13 \%$ over 4 years), while the lowest value was recorded for the orchid $(25.1 \pm 4.8 \%$ over 2 years $)$. Seed set (ratio seeds/ovules) was $47.2 \%$ for $P$. pseudoviscosa, $53.1 \%$ for $P$. montsicciana, and ranged between $63.3 \%$ and $82.4 \%$ for $B$. chouardii, while the orchid fruits contained thousands of seeds.

\subsection{Herbivory and predation}

Leaf herbivory was not detected in $A$. pyrenaica nor in $P$. montsicciana. It was negligible in $P$. pseudoviscosa (less than $5 \%$ of individuals showed signs of herbivory, in only one population), and recorded in only a low proportion of plants of $B$. chouardii and $C$. calceolus (Table 3). Leaf damage, when observed, resulted in only small losses of total biomass. In B. chouardii, $76.3 \%$ $( \pm 18.2 \%)$ of individuals subject to herbivory suffered losses of less than $25 \%$. For $C$. calceolus, $94 \%$ of the plants suffered no herbivory, and the maximum biomass loss was less than $10 \%$ of the total biomass.

Intensity of predation on reproductive organs also varied among species. It was absent in the orchid, and small in B. chouardii (less than 5\% of fruit predation for six years of monitoring). Fruit predation ranged from 0 to $37.6 \%$ in $P$. pseudoviscosa over 5 years in three different populations (Table 3).

Table 2

Census data and short-term population size change for each species ${ }^{\mathrm{a}}$

\begin{tabular}{|c|c|c|c|c|c|c|c|c|}
\hline Plant species & $\mathrm{F} 1$ & $\mathrm{~F} 2$ & $\begin{array}{l}\text { Total } N \text { in } \\
\text { Aragón }\end{array}$ & $\begin{array}{l}\text { Population } \\
\text { size range }\end{array}$ & $\begin{array}{l}\text { Mean } \pm \text { S.D. } \\
(n \text { populations })\end{array}$ & $\begin{array}{l}\text { Approx.\% } \\
\text { increasing }\end{array}$ & $\begin{array}{l}\text { Mature } \\
\text { individuals }\end{array}$ & $\begin{array}{l}\text { Finite population } \\
\text { growth rate }\end{array}$ \\
\hline Borderea chouardii & $3.5(2)$ & & 2200 & & & 340 & $1300(2: 1)$ & $0.98-1.02(n=410)$ \\
\hline Androsace pyrenaica & $2.1(9)$ & $4.1(7)$ & $18000^{*}$ & $10-3000$ & $675 \pm 866(26)$ & 80 & 11000 & \\
\hline Petrocoptis pseudoviscosa & $1.7(2)$ & $7.9(2)$ & 47000 & $100-44000$ & $9496 \pm 1957(5)$ & 370 & 18800 & $0.97-1.03(n=109-401)$ \\
\hline Petrocoptis montsicciana & $1.7(2)$ & $4-8$ & $3000^{*}$ & $80-1500$ & $468 \pm 560(6)$ & 525 & 1800 & \\
\hline Cypripedium calceolus & & & $2700^{*}$ & $6-1900$ & $909 \pm 1089(3)$ & $?$ & 915 & $0.83-1.23(n=567)$ \\
\hline
\end{tabular}

${ }^{a} \mathrm{~F} 1$ and $\mathrm{F} 2$ are the weighted average of correction factors calculated to better estimate population sizes (number of samples used in parentheses; Section 2 for further details). Total $N$ refers to the number of individuals estimated to be growing in Aragón (for B. chouardii and $P$. pseudoviscosa it represents the total for the species). The asterisk indicates the species has more populations outside the regional limits. Increasing (\%) relates current data to the last estimation published before our study (Sainz Ollero et al., 1996). For the dioecious species, the sex ratio (males:females) is also given in parentheses. $n$, Initial number of individuals monitored on which finite population growth rate was calculated.

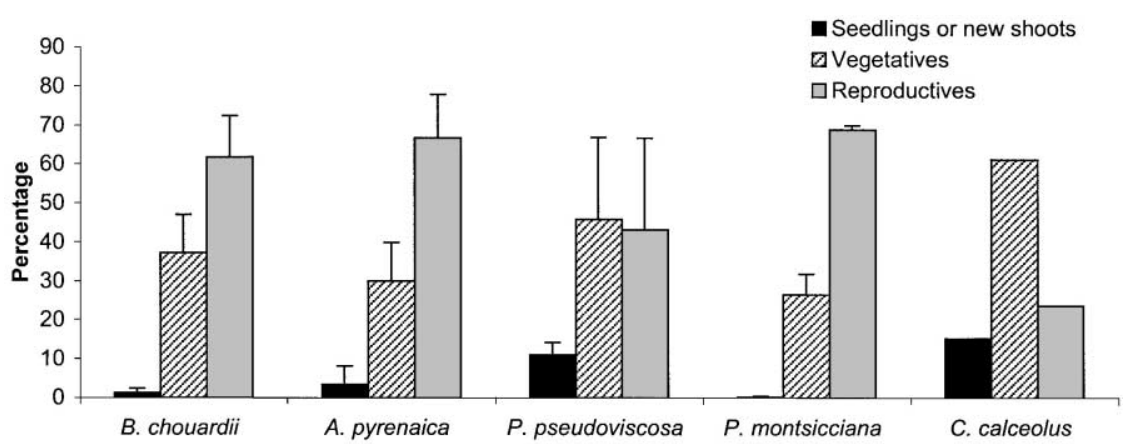

Fig. 2. Proportion of different life-stage classes of the five threatened Pyrenean species investigated, and among-population variability (mean \pm S.D.). 


\section{Discussion}

\subsection{Is there any evidence of past or current declines?}

In the absence of data from the fossil record, it is uncertain whether any of the rupicolous species examined in this study were more widely distributed in the past than they are today. Because nearly the whole potential habitat of $B$. chouardii has now been investigated in the one valley in which it is known, it is unlikely that new populations will be discovered. A similar conclusion applies to $P$. pseudoviscosa, as different allopatric taxa occur in the neighbouring valleys. For the other species, there is still some unexplored potential

\section{B. chouardii}

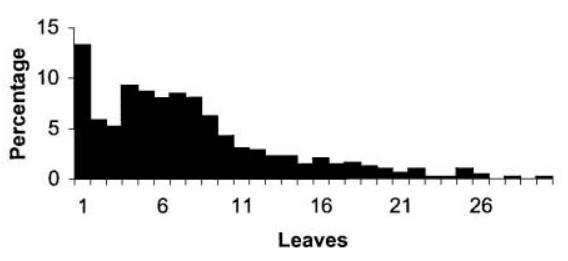

A. pyrenaica

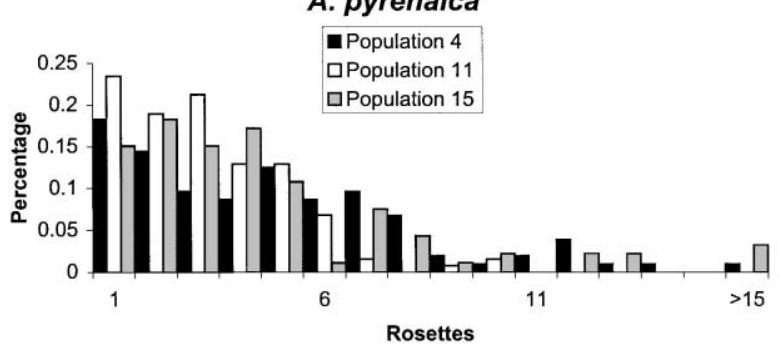

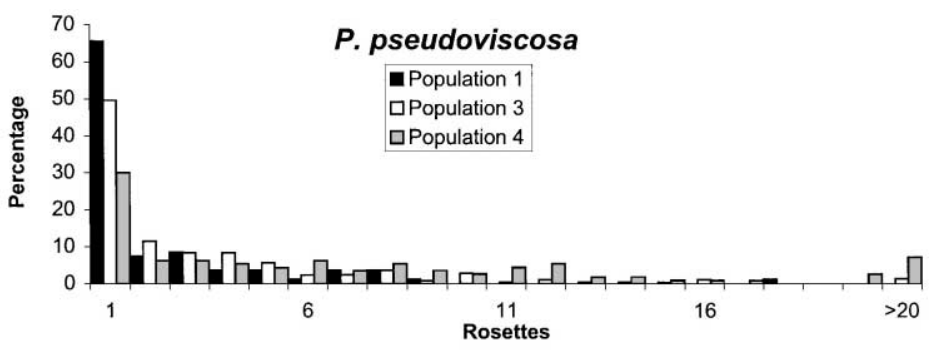

C. calceolus

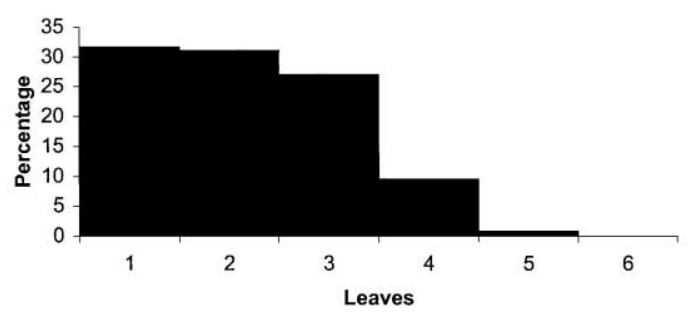

Fig. 3. Size distribution of four Pyrenean threatened species in the Aragón Pyrenees, as determined by number of leaves or number of rosettes per plant. Each histogram represents one species. For Androsace pyrenaica, only the three populations with higest sample size are presented. Each bar is the percentage of the plants in the population that occur in the respective size class.

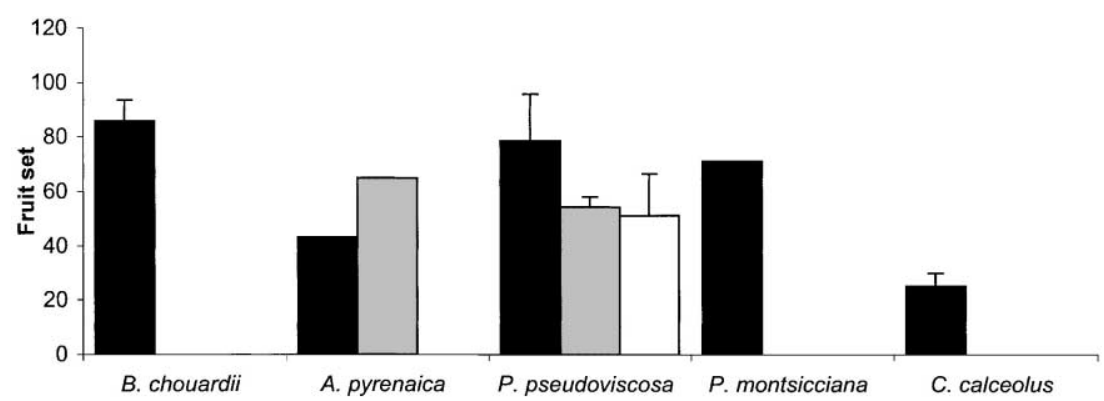

Fig. 4. Mean \pm S.D. (among year variability) of fruit set of the five threatened Pyrenean species. Different populations are represented by different bars. Borderea chouardii: data from 1995-2000 ( $n=42-309$ flowers checked); Androsace pyrenaica data from Fernández et al. (1993), Sainz Ollero et al. (1995), and our own data (1997); Petrocoptis pseudoviscosa: 1995-1998 ( $n=27-2716$ flowers); Petrocoptis montsicciana: 1993 ( $n=693$ flowers); Cypripedium calceolus: 1997-1998 ( $n=144-410$ flowers).

Table 3

Herbivory and predation: the percentage of individuals that suffered leaf damage, and reproductive units predated to some extent (the year and number of populations investigated are between parenthesis)

\begin{tabular}{|c|c|c|}
\hline & Frequency $(\%)$ & Plant part \\
\hline Borderea chouardii & $7.4 \pm 5.3(1995-1998)$ & leaves \\
\hline Androsace pyrenaica & & - \\
\hline \multirow[t]{2}{*}{ Petrocoptis pseudoviscosa } & $13.8 \pm 10.8(3$ populations $1994-1997)$ & flowers \\
\hline & $18.6 \pm 17.8(3$ populations $1994-1997)$ & fruits \\
\hline Petrocoptis montsicciana & & - \\
\hline Cypripedium calceolus & 8.6 (meadow 1997)-19.3 (forest 1997) & leaves \\
\hline
\end{tabular}


habitat, but current information suggests they are all "naturally" rare species, occurring in highly specific habitats.

There are signs suggesting that some populations have been compromised. For example, when the "Escalés" dam was constructed in the 1950 s less than $1 \mathrm{~km}$ away from the population of B. chouardii, stone for the project was quarried from the wall on which a large part of the current population grows, and a road was constructed through the population and was widened in the 1980s. This probably removed or buried some groups of plants (personal observation and P. Montserrat, personal communication, respectively). P. pseudoviscosa has also suffered some decline due to human disturbance, as the construction of a road in the 1960s passed through the largest population and eliminated a small fraction of the habitat where plants grow.

Excepting the above-noted perturbations, our results suggest that no rupicolous population reported in previous publications has disappeared, and new populations of these four rupicolous species have been found over the last 10 years (Ferrández et al., 1993; Sainz Ollero et al., 1996; this study).

Our census method clearly enhanced the detection power of individuals, so that estimates of population sizes increased by two to eight times the estimates by naked eye. This fact, together with the recent discovery of nuclei or populations noted above, resulted in total population sizes up to five times the previously published values for the rupicolous species (Sainz Ollero et al., 1996 for the Aragonese populations, Domínguez et al., 1996). They surpass considerably the median of 120 individuals recorded for species included in the US Endangered Species Act (Wilcove et al., 1993), and match the effective population size of 500 individuals clasically proposed (Franklin, 1980; Soulé, 1980). Some of them even meet the recent estimates of several thousand individuals necessary to maintain normal levels of potentially adaptive genetic variance in quantitative characters under a balance between mutation and random genetic drift (Lande, 1995). In addition, our shortterm monitoring over the last 6 years resulted in population growth rates very close to one, indicating a current high stability. Therefore, from a demographic point of view the overall situation of the rupicolous species appears somewhat better than past assessments suggested.

The orchid (C. calceolus), however, deserves special attention, as its decline has been substantial, not only in Aragón, but also in Europe, largely as the result of human perturbation (Stewart, 1992; Kull, 1999). Three of the nine populations in Aragón are known to have disappeared, each of which had probably consisted of fewer than 10 individuals (informant sources, personal communication). However, some new nuclei that we consider to be a metapopulation (considered to be three populations by our informants), have been relocated to a remote and rarely visited area. In the largest known population, one or more genets were removed by poaching in 1995, and disturbance by well-meaning naturalists and photographers who visit this population yearly might also be a problem. Seedlings and small non-flowering individuals have been trampled, and the already thin layer of soil in the meadow has been compacted and eroded. The geometric mean of population growth rates indicated that this population remained stable for the last 4 years, but the trend has been descendent over time.

\subsection{Is there evidence that these species are not performing well?}

Population structure provides a snapshot of the current demographic situation, from which some insights can be drawn (e.g. Baskin and Baskin, 1986; Oostermeijer et al., 1994; Widyatmoko and Norton, 1997). It is important, however, to keep in mind that there are no universal rules for interpreting population structure, as distribution shapes and abundances of different life stage classes might differ considerably among and even within species, depending not only on population trends, but simply on the local past history of the place, or the life history of the species in a particular habitat (e.g. Oostermijer et al., 1994, Horvitz and Schemske, 1995). In this study, size-class structure analysis showed populations skewed so that in general small size classes contained more individuals than large size classes. This suggests at least some recruitment by sexual reproduction, although the proportion of seedlings is very low.

Longevity of individuals affects population dynamics, as a lack of seedlings during the year of recording or a series of years, for example, has different consequences for an annual than for a short-lived or long-lived plant. Borderea shows one of the longest known life spans for any herbaceous plant ( $>300$ years; see compiled data by Noodén, 1988), similar to its congener B. pyrenaica and the alpine cushion Silene acaulis (dated both over 300 years, García and Antor, 1995; Morris and Doak, 1998, respectively). The few specimens examined of $A$. pyrenaica and $C$. calceolus indicated that they might be older than 30 years (possibly older than 100 years for $C$. calceolus, Kull, 1999). The very slow growth found in a study of hundreds of $P$. pseudoviscosa individuals we monitored for 6 years suggests that they also have a long life span. The rupicolous species studied here have a long life span, probably as a consequence of strong selection in very stressful habitats where growth is slow and colonization infrequent. Long life spans may buffer populations against rapid extinction because of a series of "bad years" for reproduction or germination, if extant individuals survive (Watson et al., 1997). Annual 
seedling recruitment becomes less important in this context, due to the long period each plant has to replace itself (Pierson and Turner, 1998).

None of the five species seems to have reproductive problems. Seed production is the only mechanism by which the four rupicolous species can sustain themselves, and our results indicated that fruit set is occurring at least at a level comparable to species with a similar reproductive system in each case, both for the dioecious genus (Borderea) and the self compatible genus (Petrocoptis, see data compiled by Sutherland and Delph, 1984). Fruit set was higher in the orchid than has been reported previously for other European populations (Kull, 1998) or congeners (Primack and Hall, 1990; Nilsson, 1992). Seed viability was very high for the three species we germinated in Petri dishes $(B$. chouardii, P. pseudoviscosa and P. montsicciana), and they can germinate for at least 3 years after being released in the field (J.M. Iriondo et al., unpublished data, M.B. García, unpublished data).

Herbivory cannot be considered important as levels were low. Flower and fruit predation was detected only in one species ( $P$. pseudoviscosa), and data recorded in three populations over 4 years do not indicate a substantial loss of seeds (Table 3). Nevertheless, the main reproductive problem facing rupicolous species is seedling establishment, given the limited availability of crevices scattered on the rocks, and the difficulty of seed dispersal itself. Although all of them share the same adaptation to overcome this problem (orienting fruit pedicels towards the wall to release seeds near or inside crevices), most seeds simply fall when released from the fruit (M.B. García, unpublished data), thus being lost from the population. A quantitative model is necessary to investigate to what extent the loss of seeds is affecting population dynamics, as microsite availability might be a more important factor in this particular habitat.

\subsection{What does "threatened" mean in each case?}

Our results suggest that if lack of disturbance is maintained, at least the short-term prospects for population stability of the rupicolous species are not so bad. However, B. chouardii is highly vulnerable due to the susceptibility of its single population to catastrophic local events.

Under natural conditions, both demographic and environmental stochasticity have been claimed as important factors in determining viability of species with limited distributions and/or small population sizes. However, the long life span of the species studied here is a buffer against random fluctuations in births and deaths. On the other hand, the high habitat specificity of rupicolous species might compromise recovery after possible anthropogenic disturbances. But most populations are located in inaccessible places and bare rock without much economic interest, which improves their prospects for continued protection. Therefore, preservation of their habitat, for which there is currently little human demand, is the most straightforward and logical management measure, as their persistence in the future will depend largely on the stability of their environment.

The orchid, however, having a wider distribution and probably a lower habitat specificity, represents a different situation. The population monitored seems to be stable, but the reduction in the number of its populations has been marked in the recent past, and there is evidence that such reduction is caused by human disturbance. The necessity for a conservation policy that guaranties habitat preservation becomes more urgent than for the rupicolous species (except B. chouardii), if priorities have to be established.

Based on currently available information on their distribution, demography and biology, we have evaluated the status and natural vulnerability of all the five taxa according to the IUCN (1994) criteria and the more specific plant-oriented criteria proposed by Keith (1998; Table 4). Only one species would differ in the "threat" status within the area of our study according to both classifications. A. pyrenaica should be down-listed considering that there are many more populations and individuals than when it was cataloged as "in risk of extinction" by the Regional Government. On the other hand, if criteria were applied over the entire range of the species, then their situation could improve considerably if we assume similar results elsewhere. $A$. $p y r$ enaica, for example, has at least 17 more populations at the French side of the Pyrenees, while P. montsicciana has a wider distribution in the adjacent region within Spain and C. calceolus is more common in other European countries. On a continental scale, only two of the five species would then be considered threatened, and the three remaining ones could be down-listed (Mace and Lande, 1991).

For those countries where mountains shelter numerous endemics, as in the Mediterranean basin (GómezCampo, 1985; Domínguez et al., 1996; Médail and Verlaque, 1997), many of them were probably included in lists of threatened species without reliable or even basic information on the number, sizes, and dynamics of populations. These lists should be updated after using the most objective criteria possible. This attempt will call attention to our lack of knowledge for many species, and force us to gather such basic information. That would enable us to prioritize our lists of threatened species and thus we could develop more appropriate management practices, from habitat preservation to special active interventions.

Our research is an example of a project addressed to that purpose. We have tried to assess the real vulnerability of species based on exhaustive (but simple and 
Table 4

Current status of the five Pyrenean species from Aragón included in the Habitats Directive, following the Red List Categories criteria, and the modification proposed by Keith (1998)

\begin{tabular}{lllll}
\hline & IUCN (1994) & Criteria & Keith (1998) & Criteria \\
\hline Borderea chouardii & Critically endangered & B + B1 + B2 & Critically endangered & F \\
Androsace pyrenaica & Vulnerable in Aragón & D2 & Vulnerable in Aragón & D2 \\
Petrocoptis pseudoviscosa & Vulnerable & D2 & Endangered & B + B1 + B4b + B5 \\
Petrocoptis montsicciana & Vulnerable in Aragón & D2 & Vulnerable in Aragón & B + B1 + B4 + B5 or D1 \\
Cypripedium calceolus & Endangered in Aragón & A1 or B + B1 + B2d or C1 & Endangered in Aragón & A1 or B + B1 + B2d + B5 \\
\hline
\end{tabular}

not so expensive) work in the field, where plants live, rather than on a theoretically assumed potential vulnerability. In this way, conservation efforts can address the real problem of the species. Official catalogues would serve the purpose for which they were created: as starting points for plant management practices designed to preserve these unique genetic assets.

\section{Acknowledgements}

We are much indebted to J.A. Sesé and J.V. Ferrández for invaluable information on locations of $A$. pyrenaica and P. montisicciana. Different people provided us with information and help during the field work, material, ideas, or technical assistence in different ways while elaborating results: R. Antor, J.L. Benito, C. Blanché, J. Ehrlén, J. Fabo, A. Ferrer, F. Fillat, A. Green, A. Guzmán, P. Jordano, C. Lahoz, E. Laplaza, G. Largier, J.P. Martínez-Rica, P. and G. Montserrat, M. Munárriz, J. M. Navarro, Patricia, P. Ortega, J. L. Sanz, and L. Villar. The study was funded by Gobierno de Aragón and the European Union (LIFE96NAT/E/ 3096). It was a pleasure to work together with people in the Regional Governement, including J. Guiral (who promoted this project), J. Puente, M. Alcántara, and I. Navascués. Our thanks also to R. Antor, J. Cheeseman, C.M. Herrera, K.P. Hogan and two anonymous referees, who kindly improved this manuscript both from a linguistic perspective and through fruitful discussions to clarify many of the ideas presented.

\section{References}

Anon., 1992. Directiva 92/43/CEE del Consejo, relativa a la conservación de los hábitats naturales y de la fauna y flora silvestres. Diario Oficial de Las Comunidades Europeas.

Anon., 1995a. Decreto 239/1994, de 28 de diciembre, de la Diputación General de Aragón, por el que se establece un régimen de protección para Borderea chouardii (Gaussen)Heslot y se aprueba el plan de recuperación. Boletín Oficial de Aragón 3, 54-59.

Anon., 1995b. Decreto 49/1995, de 28 de marzo, de la Diputación General de Aragón, por el que se regula el Catálogo de Especies Amenazadas de Aragón. Boletín Oficial de Aragón 42, 1270-1275.

Aymerich, P., 1999. Los zuecos: una rara y bellísima orquídea del Pirineo. Quercus 155, 39-43.
Bañares, A., 1994. Recuperación de la flora amenazada de los Parques Nacionales Canarios. Metodología para su planificación y ejecución. Ecología 8. 227-244.

Baskin, J.M., Baskin, C.C., 1986. Some considerations in evaluating and monitoring populations of rare plants in successional environments. Natural Areas Journal 6, 26-30.

Bolos, O. de, Rivas-Martínez, S., 1968. Comentarios sobre el Género Petrocoptis. Petrocoptis montsicciana sp. nova. Anales Instituto Botánico J.A. Cavanilles 26, 53-60

Domínguez, F., Galicia, D., Moreno, L., Moreno, J.C., Sainz, H., 1996. Threatened plants in Peninsular and Balearic Spain: a report based on the EU Habitats Directive. Biological Conservation 76, $123-133$.

Fernández Casas, F.J., 1973. Estudios sobre el género Petrocoptis A Br. (Caryophyllaceae). Cuadernos Ciencias Biologpeía 2, 43-45.

Ferrández, J.V., Sesé, J.A., Villar, L., 1993. Androsace pyrenaica Lam. (Primulaceae): planta endémica del Pirineo central. Corología, ecología y conservación. Lucas mallada 5, 93-100.

Franklin, I.R., 1980. Evolutionary change in small populations. In: Soulé, M.E., Wilcox, B.A. (Eds.), Conservation Biology: and Evolutionary-Ecological Perspective. Sinauer, Sunderland, MA, pp. $135-150$.

García, M.B., Antor, R.J., 1995. Age and size structure in populations of a long-lived dioecious geophyte: Borderea pyrenaica (Dioscoreaceae). International Journal of Plant Sciences 156, 236-243.

Gaussen, H., 1952. Une nouvelle espèce de Dioscorea aux Pyrénées: D. chouardii. Bulletin Societé Botanique France 99, 23-25.

Gómez-Campo, C. (Ed.), 1985. Plant Conservation in the Mediterranean area. Dr. W. Junk Publishers, Dordrecht.

Gómez-Campo, C., Malato-Beliz, J., 1985. The Iberian Peninsula. In: Gomez-Campo, C. (Ed.), Plant Conservation in the Mediterranean Area. Dr. W. Junk Publishers, Dordrecht, pp. 47-70.

Horvitz, C.C., Schemske, D.W., 1995. Spatiotemporal variation in demographic transtitions of a tropical understory herb: projection matrix analysis. Ecological Monographs 65, 155-192.

Hulten, E., Fries, M., 1986. Atlas of North European Vascular Plants. North of the Tropic of Cancer. I. Koeltz Scientific Books, Königstein. IUCN, 1994. Red List Categories. IUCN, Gland.

Juanchich, M., Lewin, J.-M., Cauwet-Marc, A.-M., 1991. Cypripedium calceolus L. (Orchidaceae) dans la partie Orientale des Pyrenees. Le Monde des Plantes 442, 19-20.

Keith, D.A., 1998. An evaluation and modification of World Conservation Union Red List criteria for classification of extinction risk in vascular plants. Conservation Biology 12, 1076-1090.

Kruckeberg, A.R., Rabinowitz, D., 1985. Biological aspects of endemism in higher plants. Annual Review of Ecology and Systematics $16,447-479$.

Kull, T., 1998. Fruit set and recruitment in populations of Cypripedium calceolus L. in Estonia. Botanical Journal of the Linnean Society 126, 27-38.

Kull, T., 1999. Biological flora of the British Isles. Cypripedium calceolus. Journal of Ecology 87, 913-924.

Lande, R., 1995. Mutation and conservation. Conservation Biology 9, 782-791. 
Lazare, J.J., Miralles, J., Villar, L., 1987. Cypripedium calceolus L. (Orchidaceae) en el Pirineo. Anales Jardin Botánico Madrid 43, 375-382.

Lazare, J.-J., Royaud, A., 1994. Observations botaniques remarquables dans les Pyrenees. Le Monde des Plantes 450, 1-4.

Mace, G.M., Lande, R., 1991. Assessing extinction threats: toward a reevaluation of IUCN Threatened Species Categories. Conservation Biology 5, 148-157.

Mayol, M., Roselló, J.A., 1999. A synopsis of Silene subgenus Petrocoptis (Caryophyllaceae). Taxon 48, 471-482.

Médail, F., Verlaque, R., 1997. Ecological characteristics and rarity of endemic plants from Southeast France and Corsica: implications for diodiversity conservation. Biological Conservation 80, 269-281.

Menges, E.S., 1992. Stochastic modelling of extinction in plant populations. In: Fiedler, P.L., Jain, S.K. (Eds.), Conservation Biology: The Theory and Practice of Nature Conservation Preservation and Management. Chapman and Hall, New York, pp. 253-275.

Menges, E.S., Gordon, D.R., 1996. Three levels of monitoring intensity for rare plant species. Natural Areas Journal 16, 227-237.

Montserrat, P., Casas, J.F., 1990.Petrocoptis. In: Castroviejo, S., et al. (Eds.), Flora Iberica. Real Jardín Botánico, Madrid, pp. 304-312.

Morillo, C., Gómez-Campo, C., 2000. Conservation in Spain, 1980 2000. Biological Conservation 95, 165-174.

Morris, W.F., Doak, D.F., 1998. Life history of the long-lived gynodioecious cushion plant Silene acaulis (Caryophyllaceae), inferred from size-based population projection matrices. American Journal of Botany 85, 784-793.

Nilsson, L.A., 1992. Orchid pollination biology. Trends in Ecology and Evolution 7, 255-259.

Noodén, L.D., 1988. Whole plant senescence. In: Noodén, L.D., Leopold, A.C. (Eds.), Senescence and Aging in Plants. Academic Press, London, pp. 391-439.

Oostermeijer, J.G.B., Van't, R., de Nijs, J.C.M., 1994. Population structure of the rare, long-lived perennial Gentiana pneumonanthe in relation to vegetation and management in the Netherlands. Journal of Applied Ecology 31, 428-438.
Pierson, E.A., Turner, R.M., 1998. An 85-year study of saguaro (Carnegiea gigantean) demography. Ecology 79, 2676-2693.

Primack, R.B., Hall, P., 1990. Costs of reproduction in the pink lady's slipper orchid: a four-year experimental study. American Naturalist $136,638-656$.

Sainz Ollero, H., Franco, F., Arias, J., 1996. Estrategias para la conservación de la flora amenazada de Aragón. Consejo de Protección de la Naturaleza de Aragón, Zaragoza.

Schemske, D.W., Husband, B.C., Ruckelshaus, M.H., Goodwillie, C., Parker, I.M., Bishop, J.G., 1994. Evaluating approaches to the conservation of rare and endangered plants. Ecology 75, 584-606.

Shaffer, M.L., 1981. Minimum population sizes for species conservation. Bioscience 31, 131-134.

Soulé, M.E., 1980. Thresholds for survival: maintaining fitness and evolutionary potential. In: Soulé, M.E., Willcox, B.A. (Eds.), Conservation Biology. Evolutionary-Ecological Perspective. Sinauer Associates, Sunderland, pp. 151-169.

Stebbins, G.L., 1980. Rarity of plant species: a synthetic viewpoint. Rhodora 82, 77-86.

Stewart, J., 1992. La Conservation des Orchidées européennes. Conseil de l'Europe.

Sutherland, S., Delph, L.F., 1984. On the importance of male fitness: patterns of fruit-set. Ecology 65, 1093-1104.

Walters, S.M., 1993. Petrocoptis. In: Tutin et al. (Eds.), Flora Europaea 2nd. Edition. Cambridge University Press.

Watson, I.W.M., Westoby, A., Holm, McR., 1997. Continuous and episodic components of demographic change in arid zone shrubs: models of two Eremophila species from Western Australia compared with published data on other species. Journal of Ecololy 85, 833846.

Widyatmoko, D., Norton, D.A., 1997. Conservation of the threatened shrub Hebe cupressoides (Scrophulariaceae), Eastern South Island, New Zealand. Biological Conservation 82, 193-201.

Wilcove, D.S., McMillan, M., Winston, K.C., 1993. What exactly is an endangered species? An analysis of the U.S. endangered species list: 1985-1991. Conservation Biology 7, 87-93. 